\title{
A Comparative Expected Value Analysis Study to Determine if the Economic Benefits of Screening and Early Diagnosis Treatment of the Most Commonly Recognized Types of Disease in the United States Provide Economic Value
}

\author{
S. Eric Anderson ${ }^{1}$, Jim Pinder ${ }^{2}$, Armond Manassian ${ }^{3}$ \\ 1,2,3 La Sierra University, Riverside, California
}

\begin{abstract}
It was found that Asthma, Chronic Obstructive Pulmonary Disease, Diabetes, Hepatitis C and HIV / AIDS screening and early diagnosis with treatment provided economic value, while Alzheimer's, Attention Deficit Hyperactivity Disorder, Cardiovascular Disease, Creutzfeldt-Jakob and Mood Disorder (depression) screening and early diagnosis with treatment were not found to have provided economic value. The current evidence is insufficient to determine if screening and early diagnosis treatment for Sleep Apnea provides economic value.
\end{abstract}

KEYWORDS: Disease, cost to screen, expected cost to treat, early diagnosis treatment cost, late diagnosis treatment cost, and economic value.

\section{INTRODUCTION}

A comparative expected value analysis study is a straight forward method to determine the financial viability of investing healthcare dollars in the early detection and treatment for a range of illnesses or disorders. This approach can be utilized to analyse the likelihood that detecting and treating certain conditions will result in a cost reduction or savings that exceeds the cost to conduct the screening or early intervention. For this study, 11 diseases or illnesses were considered, using data from government sources and other published research.

\section{RESULTS}

Alzheimer's - The United States Preventive Services Task Force concludes that the current evidence is insufficient to assess the balance of benefits and harms of screening for cognitive impairment in older adults. According to the Alzheimer's Association 1) Alzheimer's costs on average $\$ 341,000$ to cover the health needs of someone from diagnosis to death, 2) families pay $70 \%$ of this out of pocket, 3) the cost of care is projected to increase to $\$ 1.1$ trillion by 2050 and 4) patient numbers are expected to climb from 53 million in 2018 to 88 million in 2050. The average cost of Medicare in 2019 for patients 65 years and older with Alzheimer's or other dementias was estimated at $\$ 25,213$ per person, which is about 3 times higher than those without Alzheimer's (Alzheimer's Association,

2020). The costs of informal care were estimated to be $\$ 20,590$ for the baseline year, and increased to $\$ 43,031$ in year
4 as informal caregiver costs increase $18 \%$ per year as symptoms of the disease progress (Rattinger et al, 2015).

There is no single test for dementia due to Alzheimer's disease. Instead, physicians (often with the help of specialists such as neurologists, neuropsychologists, geriatricians and geriatric psychiatrists) use a variety of approaches and tools to help make a diagnosis

(Alzheimer's Association, 2020). None of the pharmacologic treatments (medications) available today for Alzheimer's dementia slow or stop the damage and destruction of neurons that cause Alzheimer's (Alzheimer's Association, 2020). The Food and Drug Administration recently approved the first drug since 2003 for the treatment of Alzheimer's. The cost is estimated to be $\$ 56,000$ per year. Data was not available for this study to determine the expected cost savings of using this drug to treat the early stages of the disease (Cubanski et al, 2021) Antipsychotics may be prescribed to treat hallucinations, aggression and agitation (Ralph et al, 2018). However, some antipsychotics are associated with increased risk of stroke and death in individuals with dementia (Maust et al, 2015). Non pharmacologic treatments for agitation and aggression in people with dementia concluded that non pharmacologic interventions seemed to be more effective than pharmacologic interventions for reducing aggression and agitation (Watt et al, 2019).

Exercise has a positive effect on overall cognitive function and may slow the rate of cognitive decline in people with Alzheimer's dementia (Farina, 2014). Cognitive stimulation does have beneficial effects on cognitive function and some 
aspects of well being in people with Alzheimer's dementia (Aguirre et al, 2013). The World Health Organization (2019) recommends physical activity, quitting smoking, and managing hypertension as well as diabetes to reduce the risk of cognitive decline. Physical activity appears to be effective in reducing risk (Ogino et al, 2019) and there is evidence heart healthy diets may be associated with reduced dementia risk (Barberger-Gateau, 2007). Vitamins C, D and E, omega 3 fatty acids, and ginkgo biloba provide little to no benefit in preventing cognitive decline (Butler et al, 2018).

There isn't an effective treatment with early or late diagnosis so early identification would not provide value. The most effective way to delay or reduce the risk of

Alzheimer's is exercise and diet. However, this also extends life, which increases the risk and prevalence of Alzheimer's. Most, but not everyone gets dementia. The longer you live, the greater your risk, but not everyone will get dementia no matter how long they live.

Asthma - According to the CDC (2018), more than 25 million Americans have asthma with $7.7 \%$ adults of and $8.4 \%$ children. A spirometry test costing around $\$ 100$ is the best way to diagnose and provides economic benefit for those who have asthma and those who don't have asthma. If the spirometry test is negative then the patient will save roughly $\$ 150$ a month on asthma medicines (Thoracic, 2018). If the doctor assumes that the patient has asthma without giving a spirometry test and the patient doesn't have asthma then the real cause of symptoms would not be treated. Without the test a doctor might assume the cause of the symptoms is a mild problem, when in fact it is asthma. If the spirometry test determines that one has asthma then they can be treated for it reducing the probability of an expensive emergency department visit for an asthma attack.

During 2014-2015, patients who had asthma documented in the medical record accounted for $9.5 \%$ of all ED visits in the United States, with the highest percentage for children aged 5-17 years (13.6\%), compared with $6.6 \%$ for children aged 0-4 years, 9.9\% for adults aged 18-64 years, and 6.5\% for those aged $\geq 65$ years (Quick Stats, 2018). The number of emergency department visits with asthma as a primary diagnosis is 1.6 million in the United States (CDC, 2017), which suggests that there is a $6.4 \%$ (1.6 million / 25 million) probability of an emergency department visit by an asthmatic. On average, an asthma-related trip to the ED costs $\$ 1,502$ (Wang, 2014) resulting in the expected value of an avoided ED visit to be $\$ 96(\$ 1,502 * .064)$. Untreated asthma can cause lung scarring, which can lead to COPD (Choosing Wisely, 2014), but the cost has not yet been quantified. The annual per-person medical cost of asthma was $\$ 3,266$. Of that, $\$ 1,830$ was for prescriptions, $\$ 640$ for office visits, $\$ 529$ for hospitalizations, $\$ 176$ for hospital outpatient visits and $\$ 105$ for emergency room care (Thoracic, 2018).
The expected benefit for either a positive and negative spirometry test would exceed the $\$ 100$ cost for the test. At Boston Children's Hospital, an asthma program that sends community health workers into patients' homes to reduce the environmental triggers of asthma has saved $\$ 1.46$ in healthcare costs for every $\$ 1$ invested. It has reduced asthmarelated hospital admissions by $80 \%$ and asthmarelated emergency department visits by 60 percent, reports the Trust (Thoracic, 2018). What is the cost to treat asthma late stages?

Attention Deficit Hyperactivity Disorder - The United States Preventive Services Task Force concludes that the current evidence is insufficient to assess the balance of benefits and harms of screening for attention deficit hyperactivity disorder. The average cost to test for attention deficit hyperactivity disorder in the Midwest is $\$ 686$ (Consumer Reports, 2010). In the United States $9.4 \%$ of those between ages 2 to 17 are diagnosed with attention deficit hyperactivity disorder (Danielson, 2016), while the global average is $2.8 \%$ (Fayyad, 2017). The annual cost of caring for children with ADHD is $\$ 2,720$ (Doshi et al, 2012). Delaying or taking a child off ADHD medication may cause ADHD symptoms to continue or reappear, but it won't have a lasting impact (Bhandari, 2020), which seems to suggest that there is no additional treatment cost for late diagnosis versus early diagnosis and treatment. Therefore early diagnosis of Attention Deficit Hyperactivity Disorder would not provide economic value.

Chronic Obstructive Pulmonary Disease - Fourteen percent of US adults aged 40 to 79 years have chronic obstructive pulmonary disease (COPD) and it is the third leading cause of death in the United States (USPSTF, 2016). According to MDsave.com, the cost of a Pulmonary Function Test (PFT) averages $\$ 587$ (ranging from $\$ 341$ to $\$ 833$ ), resulting in an expected value screening cost of $\$ 4,192$ (\$587 / .14) in asymptomatic adults. As a result, the United States Preventive Services Task Force recommends against screening for chronic obstructive pulmonary disease (COPD) in asymptomatic adults. However, the expected value screening cost if limited to symptomatic adults would provide economic value if $50 \%$ of the symptomatic adults with COPD risk factors had COPD. This would result in an expected value cost of around $\$ 1,174(\$ 587 / .5)$. The cost of treatment for Stage I COPD patients was $\$ 1,681$ per patient per year and stage II COPD costs were $\$ 5,037$ per patient per year resulting in a $\$ 3,356(\$ 5,037$ - \$1,681) per year savings exceeding the $\$ 1,174$ expected value cost of screening symptomatic adults (Chapman, et al, 2006) if the COPD was diagnosed in Stage 1 instead of Stage II. Stage III COPD treatment costs were $\$ 10,812$ per patient per year resulting in a $\$ 9,131(\$ 10,812$ $\$ 1,681$ ) per year savings greatly exceeds the $\$ 1,174$ expected value cost of screening symptomatic adults if the COPD was diagnosed in Stage 1 instead of Stage III (Chapman et al, 2006). 
Cardiovascular Disease - The USPSTF recommends against screening with resting or exercise electrocardiography (ECG) to prevent cardiovascular disease (CVD) events in asymptomatic adults at low risk of a CVD event. Sixteen studies found no significant improvement for screening with an exercise ECG (vs no screening) in adults aged 50 to 75 years (Jonas et al, 2018). According to MDsave.com the average cost of a stress test and ECG is \$407. The Institute of Medicine Report (2011) estimated 16.3 million Americans aged 20 and older (7\%) have CVD which would result in a $\$ 5,814$ (\$407 / .07) expected cost to screen. The average medical direct medical costs were $\$ 18,953$ per person and the greatest differences in costs were found between those that were hospitalized at $\$ 62,755$ per person and those who weren't hospitalized at $\$ 13,509$ per person (Gregory et al, 2010) a difference of $\$ 49,243$. Every year, 605,000 Americans have a heart attack for the first time (Weatherspoon, 2020) and there are around 110 million or roughly $34 \%$ of the US population over the age of 50 . This means that only $.55 \%$ (110 million / 605,000) are first time heart attackers. It is extremely unlikely that the all those who had the resting or exercise electrocardiography (ECG) would avoid a heart attack followed by the subsequent hospitalization. Even if this were to happen the expected cost of screening per person and the avoidance of per person hospitalization at $\$ 74,000(\$ 407 / .0055)$ is greater than the cost of hospitalization at $\$ 62,755$.

Creutzfeldt-Jakob (Mad Cow) - There is no known way to prevent sporadic Creutzfeldt-Jakob (CJD) or to treat it. The risk of contracting CJD in the United States remains extremely low evident by the fact that there have been only three cases reported in the United States (USFDA, 2020).

According to the Centers for Disease Control and Prevention, strong evidence suggests that these cases were acquired abroad - two in the United Kingdom and one in Saudi Arabia (Mayo Clinic, 2020). Treatment for mad cow disease in humans mainly deals with keeping a patient comfortable until death, which can happen a few months to a year after symptoms start. Strong pain killers may be used to help control the pain, for instance. Doctors commonly use the electroencephalogram ( $\$ 332$ - 543), MRI $(\$ 400$ to $\$ 3,500)$ and spinal fluid tests ( $\$ 400$ to $\$ 4,000)$ to help detect CJD and there is no treatment for it and no vaccine to prevent it (Mayo Clinic, 2020). Therefore, screening and early diagnosis treatment would not provide economic value since there is no treatment for the disease and no vaccine to prevent it.

Diabetes - The cost of care for people with diabetes now accounts for 1 in 4 health care dollars spent in the United States and care for a person with diabetes now costs an average of $\$ 16,752$ per year (Riddle and Herman, 2018). As a result, the United States Preventive Services Task Force recommends screening for abnormal blood glucose as part of cardiovascular risk assessment in adults aged 40 - 70 years who are overweight or obese. The cost per case identified for each strategy was lower when screening was restricted to those individuals with a BMI of $\geq 25 \mathrm{~kg} / \mathrm{m}^{2}$ ranged from $\$ 153$ to $\$ 200$ (Zhang, 2003). Individuals with clinically-diagnosed diabetes were identified on average 2.2 years later than individuals whose diabetes was detected during routine screening practices. Healthcare costs were significantly lower in the screening group compared with the no-screening control group and the average per patient savings over 5 years if the patient was screened was $\$ 3,300$ for type 2 diabetes (Sortsø et al, 2018).

Depression (Mood Disorder) - Antidepressant medication improved symptoms in about $20 \%$ of those with depression (NCBI, 2015) and a generic antidepressant can be purchased for as little as $\$ 4$ per month or $\$ 48$ per year (Westra, 2010) Research shows that psychotherapy for depression is as effective as antidepressant medications during the treatment period (Westra, 2010). However, seeing a psychotherapist costs around $\$ 100$ per session, so a six session treatment program spread over three months would cost around $\$ 600$, which is about 12 times the annual cost for generic antidepressant medication. Pfeiffer, Heisler, Piette, Rogers and Valenstein (2010) reported no significant difference in depression outcomes between those randomized in a peer support intervention versus cognitive therapy. The cost to join a weekly support group can cost as little as $\$ 15$ per week (\$60 per month) or $\$ 180$ (three months). Goyal (2014) reported that mindfulness meditation may be just as effective as medication when it comes to the treatment of depression, and no thirdparty cost is associated with engaging in mindfulness. Likewise, exercise enhances the action of endorphins circulating throughout the body improving natural immunity and is as effective at reducing mild depression as antidepressant medications (Harvard Health Letter, 2013). The amount spent to treat depressive disorders in the United States is $\$ 71$ billion (Dieleman, Baral \& Birger, 2016), and 16.2 million adults in the United States have at least one major depressive episode in a given year (Koskie, 2018). Therefore, the cost per person (CPP) for depressive disorders in the United States is $\$ 4,382$ per person ( $\$ 71$ billion / 16.2 million). It was found that exercise and meditation provided the most value treating mild depression followed by medication, which had an annual payback period (APP) of .05. Screening doesn't seem to provide value since the one year cost to treat is less than the cost to screen.

\begin{tabular}{|l|l|l|l|l|l|l|}
\hline Programs & SR & Cost & C/SR & CPP & BPP & APP \\
\hline Exercise & $20 \%$ & $\$ 0$ & $\$ 0$ & $\$ 4,382$ & $\$ 4,382$ & .00 \\
\hline Meditation & $20 \%$ & $\$ 0$ & $\$ 0$ & $\$ 4,382$ & $\$ 4,382$ & .00 \\
\hline Medication & $20 \%$ & $\$ 48$ & $\$ 240$ & $\$ 4,382$ & $\$ 4,142$ & .05 \\
\hline Support Groups & $20 \%$ & $\$ 180$ & $\$ 900$ & $\$ 4,382$ & $\$ 3,482$ & .20 \\
\hline Psycho-therapy & $20 \%$ & $\$ 600$ & $\$ 3000$ & $\$ 4,382$ & $\$ 1,382$ & .68 \\
\hline
\end{tabular}

S. Eric Anderson', AFMJ Volume 6 Issue 07 July 2021 
Hepatitis $\mathrm{C}$ - There is no Hepatitis $\mathrm{C}$ vaccine and more than half of those who become infected will develop chronic infections (CDC, 2020). MDsave.com reported that the cost of a Hepatitis C Antibody Test is \$62. On the basis of 20132016 National Health and Nutrition Examination Survey data and considering populations not sampled in NHANES, an estimated $1 \%$ of all adults in the United States are positive for Hepatitus C. (Hofmeister et al, 2019). The approximate cost to treat is $\$ 25,000$ per course of treatment (Eckman et al, 2013) and approximately $45 \%$ of persons infected with Hepatitus $\mathrm{C}$ do not recall or report having specific risk factors (Kim et al, 2019). Tartar (2013) compared a baseline of individuals aged 40 years and people who inject drugs in the US, screening and treatment for hepatitis $C$ increased total costs by $\$ 10,457$ per person and increase QALYs by 0.23 (approximately 3 months), providing an incremental costeffectiveness ratio of $\$ 45,465$ per QALY. Universal screening and treatment for the virus increased total costs by $\$ 2,845$ per person and increase QALYs by 0.01 , providing an incremental costeffectiveness ratio of $\$ 291,277$ per QALY (Tatar et al, 2020), which is 6.4 times more costly than the targeted screening. It can take time for chronic hepatitis $\mathrm{C}$ to cause serious symptoms (Linas, 2018), but starting treatment early may lower your risk of developing complications from the illness, including liver scarring and liver cancer (Grey, 2020). Hepatitis $C$ causes damage to your liver and within 15 to 25 years of contracting hepatitis C, an estimated 20 to $30 \%$ of develop cirrhosis and without antiviral treatment, an estimated $67-91 \%$ of people with liver scarring die from liver cancer, liver failure, or other liver-related causes (Toshikuni et al, 2014). Current treatments cure over $90 \%$ with few side effects (CDC, 2021).

HIV / AIDS - The mean per-test cost of rapid HIV testing and counselling was $\$ 48.07$ for an HIV-negative test and \$64.17 for a preliminary-positive test (Pinkerton et al, 2010). The overall positivity rate at CDC funded test sites for new diagnoses was $0.4 \%$ (CDC, 2018). Over the past 15 years, those with a late diagnosis accounted for $56 \%$ of the total patient months and $68 \%$ of all costs: $70 \%$ of all drug costs, $61 \%$ of all outpatient costs, and $64 \%$ of hospital costs (Krentz et al, 2012). Those with a late diagnosis cost a mean of $\$ 1419$ $\pm \$ 378$ per month $(\$ 17,028 \pm \$ 5,031$ per year $)$ compared to $\$ 914 \pm \$ 452$ per month $(\$ 10,968 \pm \$ 5,677$ per year) for those with an early diagnosis (Krentz et al, 2012). The 15 year cost for those with a late diagnosis and treatment was $\$ 255,420$ (15 years * \$1,419 per month * 12 months) and the cost for those with early diagnosis and treatment was $\$ 164,520$ (15 years $* \$ 914 * 12$ months). Though there is no cure for HIV, early diagnosis can aid in timely initiation of antiretroviral therapy that can stop the virus from damaging the immune system.

An HIV patient who has received timely treatment can live a normal and long life without progressing to late stage HIV.
Those that are diagnosed late can start to take treatment and it will still be effective, strengthening the immune system, reducing the amount of HIV in the body and prevent illnesses. Screening does provide economic value since nearly $40 \%$ of new HIV infections are transmitted by people who don't know they have the virus (CDC, 2020).

Sleep Apnea - MDsave.com reported the cost of a sleep apnea exam (\$464) and sleep study polysomnography $(\$ 2,996)$ was $\$ 3,460$. The exact prevalence is unknown, although estimates range from $2 \%$ to $14 \%$ in communityscreened populations and $20 \%$ to $90 \%$ of persons referred for sleep studies (Myers et al, 2013). Many delay treatment due to the cost of the medical expenses failing to consider the effects and symptoms untreated sleep apnea which can undermine sleep and contribute to the complications of hypertension, diabetes, heart disease, stroke and dementia (America Sleep Apnea Association, 2021). The typical cost for sleep apnea treatment averages $\$ 19,050$ ranging between $\$ 1,800$ and $\$ 25,000$ (Real Self, 2020). CPAP and oral appliances work well, but they're not cures for sleep apnea. The only sure way to cure sleep apnea is to lose weight or have surgery to remove excess tissue from the palate or throat. Surgery can have side effects, which is why it's usually viewed as a last resort (Watson, 2013).

\section{SUMMARY}

Utilizing the 11 diseases and illnesses presented in this study, a comparative expected value analysis study was used to determine if the healthcare dollars invested in the early detection and treatment of the condition results in a net cost savings. The amount of data available for each condition varied significantly. However, the analysis provides a clear snapshot of the likely cost to detect and treat each disease or illness. Once the new FDA-approved Alzheimer's drug is used more prevalently, and additional data gathered, a more thorough analysis of this drug's ability to reduce healthcare costs can be conducted.

\begin{tabular}{|l|l|l|l|l|}
\hline $\begin{array}{l}\text { Types of } \\
\text { Disease }\end{array}$ & $\begin{array}{l}\text { Cost to } \\
\text { Screen }\end{array}$ & $\begin{array}{l}\text { Positivity } \\
\text { Rate }\end{array}$ & $\begin{array}{l}\text { Expected } \\
\text { Cost Screen }\end{array}$ & $\begin{array}{l}\text { Early } \\
\text { Treatment Cost }\end{array}$ \\
\hline ALZ & - & - & - & - \\
\hline Asthma & $\$ 100$ & $8 \%$ & - & $\$ 3,266$ \\
\hline ADHD & $\$ 686$ & $9.4 \%$ & $\$ 7,297$ & $\$ 2,720$ \\
\hline COPD & $\$ 587$ & $14 \%$ & $\$ 4,192$ & \\
\hline CJD & $\$ 1,000$ & .0000001 & $\$ 1$ billion & $\$ 1,681$ \\
\hline Diabetes & - & - & $\$ 176$ & $\$ 13,452$ \\
\hline CVD & $\$ 225$ & $7 \%$ & $\$ 3,214$ & $\$ 13,267$ \\
\hline Hep C & $\$ 62$ & $1 \%$ & $\$ 6,200$ & $\$ 13,750$ \\
\hline HIV/AIDS & $\$ 64$ & $0.4 \%$ & $\$ 16,000$ & $\$ 164,520$ \\
\hline MD & - & - & - & $\$ 240$ \\
\hline SA & $\$ 3,450$ & $55 \%$ & $\$ 6,272$ & $\$ 19,050$ \\
\hline
\end{tabular}

S. Eric Anderson"1, AFMJ Volume 6 Issue 07 July 2021 
"A Comparative Expected Value Analysis Study to Determine if the Economic Benefits of Screening and Early

Diagnosis Treatment of the Most Commonly Recognized Types of Disease in the United States Provide Economic Value"

\begin{tabular}{|l|l|l|l|l|}
\hline $\begin{array}{l}\text { Types of } \\
\text { Disease }\end{array}$ & $\begin{array}{l}\text { Early Stage } \\
\text { Treatment Cost }\end{array}$ & $\begin{array}{l}\text { Late stage } \\
\text { Treatment Cost }\end{array}$ & $\begin{array}{l}\text { Economic } \\
\text { Benefit }\end{array}$ & $\begin{array}{l}\text { US } \\
\text { PTF }\end{array}$ \\
\hline ALZ & - & - & - & I \\
\hline Asthma & $\$ 3,266$ & $\$ 3,266$ & - & - \\
\hline ADHD & $\$ 2,720$ & $\$ 2,720$ & $(\$ 7,297)$ & I \\
\hline COPD & & & $\$ 4,939$ & D \\
\hline CJD & $\$ 1,681$ & $\$ 10,812$ & $(\$ 1$ billion) & - \\
\hline Diabetes & $\$ 13,452$ & $\$ 16,752$ & $\$ 3,124$ & B \\
\hline CVD & $\$ 13,267$ & $\$ 18,953$ & $\$ 2,472$ & I \\
\hline Hep C & $\$ 13,750$ & $\$ 13,750$ & $(\$ 6,200)$ & - \\
\hline HIV/AIDS & $\$ 164,520$ & $\$ 255,420$ & $\$ 75,300$ & A \\
\hline MD & $\$ 240$ & - & - & - \\
\hline SA & $\$ 19,050$ & $\$ 25,322$ & - & I \\
\hline
\end{tabular}

HIV/AIDS, and Sleep Apnea) contributed to a growing body of literature investigating the cost-effectiveness of treatments for these diseases at various stages.

\section{REFERENCES}

1. Aguirre E, Woods RT, Spector A, Orrell M, Cognitive stimulation for dementia: A Systematic review of the evidence of effectiveness from randomized controlled trials. Ageing Res Rev 2013, 12(1):253-62.

2. Alzheimer's Association 2020 Report, Alzheimer's disease facts and figures, Alzheimer's Dement, 2020, 16:391 - 460 .

From a purely cost-saving analysis, by comparing screening and early stage diagnosis treatment costs versus late stage diagnosis treatment costs, it was found that screening and early diagnosis and treatment of Asthma, Chronic Obstructive Pulmonary Disease, Diabetes and HIV

/ AIDS provided economic value. Alzheimer's, Attention Deficit Hyperactivity Disorder, Cardiovascular Disease, Creutzfeldt-Jakob, Mood Disorder and Hepatitis C screening and early diagnosis with treatment were not found to have provided economic value. The current evidence is insufficient to assess the balance of benefits and harms of screening for Sleep Apnea. It is therefore beneficial to continue research and development into more efficient and less costly methods of screening and treatments to increase the economic benefit for all cancers.

\section{CONCLUSION}

The results of this study may potentially impact a variety of stakeholders who stand to benefit from the findings. A primary group would be individual patients who make decisions to undergo early screening and treatment based on financial considerations. Private insurance companies and hospitals constitute another group of stakeholders as they are major players on the supply side by providing early screening and treatment within the healthcare system. The cost effectiveness of these services is a major factor in determining the extent of their availability. It's important to note that politicians who deliberate public policy formulation regarding national healthcare issues would be another important category of stakeholders. The Congressional Budget Office uses the comparative expected value approach to determine the costeffectiveness of certain screenings and medical treatments as they develop healthcare policy. The methodology employed in this study is in line with those employed in similar studies within the literature. The results from the 11 diseases that were the subject of this study (Alzheimer's, Asthma, Attention Deficit Hyperactivity Disorder, Chronic Obstructive Pulmonary Disease, Cardiovascular Disease, Creutzfeldt-Jakob (Mad Cow), Diabetes, Depression (Mood Disorder), Hepatitis C, 
"A Comparative Expected Value Analysis Study to Determine if the Economic Benefits of Screening and Early

Diagnosis Treatment of the Most Commonly Recognized Types of Disease in the United States Provide Economic

Value"

treatment among U.S. children and adolescents, Journal of Clinical Child and Adolescent Psychology, 2018, 47:2, 199-212

18. Dieleman JL, Baral R, Birger M, U.S. Spending on personal health care and public health, 1996-2016, JAMA. doi:10.1001/jama.2016.16885

19. Doshi A, Hodgkins P, Kahle D, Sikirica V, Cangelosi J, Setywan J, Erder H, Neumann PJ, Economic Impact of Childhood and Adult Attention Deficit Hyperactivity Disorder in the United States, Journal of the American Academy of Child \& Adolescent Psychiatry, 2012, 51(10): 990-1002

20. Eckman MH, Talal AH, Gordon SC, Schiff E, Sherman KE, Cost-effectiveness of screening for chronic hepatitis C infection in the United States, Clin Infect Dis, 2013;56:1382-93

21. Farina N, Rusted J, Tabet N, The effect of exercise interventions on cognitive outcome in Alzheimer's disease: A systematic review, Int Psychogeriatr 2014, 26(1): 9-18

22. Fayyad J., Sampson NA, Hwang I, The descriptive epidemiology of DSM-IV Adult ADHD in the World Health Organization World Mental Health Surveys, Atten Def Hyp Disord, 2017, 9: 47-65

23. Greenland P, Blaha MJ, Budoff MJ, Erbel R, Watson KE,Coronary calcium score and cardiovascular risk, J Am Coll Cardiol. 2018; 72: 434-447

24. Goyal M, (2014) Meditation programs for psychological stress and well-being, A systematic Review and Meta-analysis, JAMA Intern Med, 2014 174(3):357-368

25. Gregory AN, Bell, TJ, Pedula KL and O'keeffeRosetti M, Medical Care Costs Among Patients With

26. Established Cardiovascular Disease, The American Journal of Managed Care, March 2010, Volume 16, Issue 3

27. Grey H, Five reasons not to delay your Hepatitis $\mathrm{C}$ treatment, Health Line, 2020 January 2

28. Harvard Health Letter, Exercise is an all-natural treatment to fight depression - Exercise is as effective as drugs in some cases, Harvard Health Publishing, 2013, August

29. Hecht HS, Coronary artery calcium scanning: past, present, and future, JACC Cardiovasc Imaging, 2015; 8: 579-596

30. Hofmeister MG, Rosenthal EM, Barker LK, et al. Estimating prevalence of hepatitis $\mathrm{C}$ virus infection in the United States, 2013-2016. Hepatology, 2019;69:1020-31

31. Institute of Medicine (US) Committee on a National Surveillance System for Cardiovascular and Select Chronic Diseases, Washington (DC), 2011
32. Jonas DE, Reddy S, Cook-Middleton J, Barclay C, Green J, Baker C, Asher GN, Screening for

33. Cardiovascular Disease Risk With Resting or Exercise Electrocardiography Evidence Report and Systematic Review for the US Preventive Services Task Force, JAMA. 2018; 319(22):2315-2328.

34. Kim HS, Yang JD, El-Serag HB, Kanwal F. Awareness of chronic viral hepatitis in the United States: An update from the National Health and Nutrition Examination Survey, $J$ Viral Hepat 2019;26:596-602

35. Koskie B, Depression, facts, statistics and you, Health Line, 2018, June 29

Krentz HB, Gill MJ, Direct Medical Costs of Late Presentation of HIV Infection over a 15-Year Period, AIDS Res Treat, 2012

36. Linas BP, Nolen S, A Guide to the Economics of Hepatitis C Virus Cure in 2017, Infectious Disease Clinics of North America, 2018, 32(2), 447-459

37. Maust DT, Kim HM, Seyfried LS, Chiang C, Kavanagh J, Schneider LS, Antipsychotics, other psycho-tropics and the risk of death in patients with dementia: number needed to harm. JAMA Psychiatry 2015, 72:438-45

38. Mayo Clinic Staff, Creutzfeldt-Jakob Disease symptoms and causes, 2020

39. Mayo Clinic Staff, Creutzfeldt-Jakob Disease diagnosis and treatment, 2020

40. Myers KA, Mrkobrada M, Simel DL. Does this patient have obstructive sleep apnea? The rational clinical examination systematic review, JAMA, 2013; 310 (7):731-741

41. NCBI, Depression: How effective are antidepressants? NCBI Report, 2015 January

42. Ogina E, Manly JJ, Schupf N, Mayeux R, Gu Y, Current and past leisure time physical activity in relation to risk of Alzheimer's disease in older adults, Alzheimer's Dement, 2019, 15(12):16031611.

43. Pinkerton SD, Bogart LM, Howerton D, Snyder S, Becker K, Asch S, Cost of Rapid HIV Testing at 45 Hospitals, AIDS Patient CARE STDS, 2010 Jul; 24(7): 409-413

44. Pfeiffer PN, Heisler M, Piette JD, Rogers M, Valenstein M, Efficacy of peer support interventions for depression: A meta-analysis, Gen Hosp Psychiatry, 2010, Jan-Feb, 33(1), 29 - 36

45. Quick Stats, Percentage of All Emergency Department (ED) Visits Made by Patients with Asthma, by Sex and Age Group - National Hospital Ambulatory Medical Care Survey, United States 2014-2015, Morb Mortal Wkly Rep 2018, 67:167 
"A Comparative Expected Value Analysis Study to Determine if the Economic Benefits of Screening and Early

Diagnosis Treatment of the Most Commonly Recognized Types of Disease in the United States Provide Economic Value"

46. Ralph SJ, Espinet AJ, Increased all-cause mortality by antipsychotic drugs: Updated review and metaanalysis in dementia and general mental healthcare. J Alzheimer's Dis Rep 2018, 2:1-26.

47. Rattinger GB, Schwartz S, Mullins CD, et al. Dementia severity and the longitudinal costs of informal care in the Cache County population. Alzheimer's Dement. 2015, 11(8):946-954.

48. Riddle MC, Herman WH, The Cost of Diabetes Care-An Elephant in the Room, Diabetes Care, 2018 May; 41(5): 929-932.

49. Sleep Apnea Association, 2021

50. Sortsø C, Komkova A, Sandbæk A, Griffin SJ, Emneus M, Lauritzen T, Simmons RK, Effect of screening for type 2 diabetes on healthcare costs, Diabetologia, 2018, 61: 1306-1314

51. Tatar M, Keeshin S, Mailliard M, Cost-effectiveness of Universal and Targeted Hepatitis C Virus Screening in the United States, 2020, Jama Network Thoracic, Asthma Costs the U.S. Economy More than $\$ 80$ Billion per Year, 2018, January 12

52. Toshikuni N, Arisawa T, Tsutsumi M. Hepatitis Crelated liver cirrhosis - strategies for the prevention of hepatic decompensation, hepatocarcinogenesis, and mortality. World J Gastroenterol 2014; 20(11): 2876-2887

53. USFDA, All about the BSE-Mad Cow Disease, 2020 54. US Preventive Services Task Force (USPSTF), Screening for Chronic Obstructive Pulmonary Disease, US Preventive Services Task Force
Recommendation Statement, JAMA, 2016, 315(13): 1372-1377.

54. Watt JA, Goodarzi Z, Veroniki AA, Nincic V, Khan PA, Ghassemi, M, Comparative efficacy of interventions for aggressive and agitated behaviors in dementia, Ann Internal Med, 2019, Oct.

55. Wang T, Srebotnjak T, Brownell J, \& Hsia RY, Emergency department charges for asthma-related outpatient visits by insurance status, Journal of Health

56. Care for the Poor and Underserved, 2014, 25(1): 396-405

57. Weatherspoon D, Heart disease facts, statistics and you, Health Line, 2020, July 16

58. Westra, H. (2010). The Effectiveness of Psychotherapy, What the research tells us, Find a Psychologist, National Registry of Health Service Psychologists

59. Watson S, Weight loss, breathing devises still best for treating obstructive sleep apnea, Harvard Health Publishing, 2013, October 2

60. Williams, C, Sleep Apnea Treatment: What you need to know, Real Self, 2020, November 23

61. World Health Organization, Risk reduction of cognitive decline and dementia: WHO guidelines, 2019.

62. Zhang P, Engelgau M, Valdez R, Banjamin SM, Cadwell B, Venkat-Narayan, KM, Costs of Screening for Pre-diabetes Among U.S. Adults: A comparison of different screening strategies, Diabetes Care, 2003 Sep; 26(9): 2536-2542.

\section{APPENDIX}

\begin{tabular}{|c|c|c|c|c|c|c|c|c|}
\hline Disease Types & $\begin{array}{l}\text { Cost to } \\
\text { Screen }\end{array}$ & $\begin{array}{l}\text { Positivity } \\
\text { Rate }\end{array}$ & $\begin{array}{l}\text { Expected Cost } \\
\text { to Screen }\end{array}$ & $\begin{array}{l}\text { Early Stage } \\
\text { Treatment Cost }\end{array}$ & $\begin{array}{l}\text { Screen \& } \\
\text { Treat Cost }\end{array}$ & $\begin{array}{l}\text { Late } \quad \text { Stage } \\
\text { Treatment Cost }\end{array}$ & $\begin{array}{l}\text { Economic } \\
\text { Benefit }\end{array}$ & USTP \\
\hline Alzheimer's & - & - & - & - & - & - & - & $\mathrm{I}$ \\
\hline Asthma & $\$ 100$ & $8 \%$ & - & $\$ 3,266$ & - & $\$ 3,266$ & - & - \\
\hline$\overline{A D D}(\mathrm{ADHD})$ & $\$ 686$ & $9.4 \%$ & $\$ 7,297$ & $\$ 2,720$ & $\$ 10,017$ & $\$ 2,720$ & $(\$ 7,297)$ & 1 \\
\hline COPD & $\$ 587$ & $14 \%$ & $\$ 4,192$ & & $\$ 5,873$ & & $\$ 4,939$ & $\mathrm{D}$ \\
\hline CJD (Mad Cow) & $\$ 1,000+$ & .0000001 & $\$ 1$ billion & $\$ 1,681$ & \$1 billion & $\$ 10,812$ & (\$1 billion) & - \\
\hline Diabetes & - & - & $\$ 176$ & $\$ 13,452$ & $\$ 13,628$ & $\$ 16,752$ & $\$ 3,124$ & B \\
\hline CVD & $\$ 225$ & $7 \%$ & $\$ 3,214$ & $\$ 13,267$ & $\$ 16,481$ & $\$ 18,953$ & $\$ 2,472$ & I \\
\hline Hep C & $\$ 62$ & $1 \%$ & $\$ 6,200$ & $\$ 13,750$ & $\$ 19,950$ & $\$ 13,750$ & $(\$ 6,200)$ & - \\
\hline HIV/AIDS & $\$ 64$ & $0.4 \%$ & $\$ 16,000$ & $\$ 164,520$ & $\$ 180,120$ & $\$ 255,420$ & $\$ 75,300$ & $A$ \\
\hline Mood Disorder & - & - & - & $\$ 240$ & - & - & - & - \\
\hline Sleep Apnea & $\$ 3,450$ & $55 \%$ & $\$ 6,272$ & $\$ 19,050$ & $\$ 25,322$ & $\$ 25,322$ & - & 1 \\
\hline
\end{tabular}

